\title{
Direito Sanitário em Perspectiva
}

Health Law in perspective

\section{Fábio Ferreira Mazza}

Graduado em Direito, especialista em Direito Sanitário e em Direito Público, Mestre em Saúde Pública. Pesquisador colaborador do Programa de Direito Sanitário da Fundação Oswaldo Cruz (Prodisa/Fiocruz). Brasília-DF, Brasil.

A obra, organizada por Sandra Mara Campos Alves, Maria Célia Delduque e Nicolao Dino Neto, é fruto da cooperação firmada entre a Escola Superior do Ministério Público da União e a Fundação Oswaldo Cruz Brasília, por meio de seu Programa de Direito Sanitário, quando da idealização do curso de Especialização em Direito Sanitário voltado para Membros do Ministério Público da União. O conteúdo presente nesta obra é a consolidação dos artigos utilizados como textos-base no curso, elaborados por profissionais do Direito e da Saúde, que conduziram a discussão e a reflexão dos docentes e discentes envolvidos.

A obra possui um total de dezessete artigos e trezentos e trinta e três páginas, estando dividida em seis eixos temáticos, da seguinte forma: Saúde e Direito: interfaces; O Sistema Único de Saúde (SUS); Saúde: questões polêmicas; A Proteção da Saúde e as Vigilâncias; Sistema Internacional e Saúde; Ética Sanitária.

O primeiro eixo temático inicia-se abordando a evolução da proteção do Direito à saúde, com destaque para a Constituição de 1988, onde a participação popular teve e ainda tem determinante papel na elaboração e desenvolvimento das ações e serviços de saúde. Este eixo temático também aborda os dilemas que o exercício da saúde/doença impõe ao brasileiro que vive em grandes cidades, onde há uma necessidade de se promover a coexistência da técnico-ciência como experiência humana no seu sentido mais íntimo. Ao término deste primeiro módulo, uma interessante discussão sobre políticas de saúde é apresentada, nos mostrando que a focalização e universalização podem ser combinadas como métodos alternativos ou complementares de implementação da noção de justiça definida.

O segundo eixo temático faz uma abordagem mais focada no Sistema Único de Saúde (SUS), ao trazer artigos que abordam o surgimento do sistema e seus desafios; o financiamento público; os modelos assistências; a atenção primária à 
saúde; a assistência farmacêutica no SUS. É interessante a reflexão trazida em um dos artigos, acerca dos avanços e desafios da política de saúde em tempos de globalização, pois o SUS está na contramão da globalização e da hegemonia das ideias neoliberais, está na contramão do atual papel do Estado em relação à sociedade e ao mercado.

Da mesma forma, outro desafio presente são os subsídios dados aos gastos privados em saúde que, juntamente com as dificuldades do SUS em dispor de recursos minimamente compatíveis com suas necessidades, geram um comprometimento na cobertura universal e igualitária do Direito à saúde.

Ainda no presente eixo, a questão das formas de prestação da atenção no SUS é discutida juntamente com algumas propostas alternativas, sendo a viabilização destas últimas dependentes da correlação de forças e pela tendência hegemônica que se firmar na organização do SUS; a lógica da demanda (mercado) ou a lógica das necessidades (direito à saúde).

É discutido também os conceitos e abordagens da atenção primária à saúde e suas transformações, ficando evidenciado que a reorganização do sistema de saúde brasileiro orientada por uma atenção primária abrangente, é um meio para a redução das desigualdades sociais e regionais no acesso e utilização de serviços de saúde, contribuindo dessa forma na efetivação do direito à saúde.

Por fim, este eixo apresenta um artigo sobre assistência farmacêutica no SUS, sendo possível concluir que os marcos legais recentes parecem trazer importantes modificações que, como consequência, ameaçam à sustentabilidade do financiamento da assistência farmacêutica em todas as esferas da federação.

O terceiro eixo temático trata de questões polêmicas da saúde, trazendo artigos que abordam o Direito fundamental à saúde e a atividade legislativa; a judicialização das políticas de saúde no Brasil; a regulação da saúde, desafios e as agências reguladoras setoriais (ANVISA e ANS); democracia e saúde, o papel do Ministério Público nas instâncias participativas sanitárias; entidades filantrópicas e a relação público/privada no SUS. O eixo inicia-se com um artigo que avalia a relação entre o direito à saúde como um direito fundamental e a atividade legislativa decorrente, deixando claro a imprescindibilidade da atividade legislativa na concretização do direito à saúde. Em seguida, faz-se uma discussão acerca do fenômeno da judicialização das políticas de saúde no Brasil, ficando evidenciado que 
as excessivas demandas judiciais de caráter individual comprometem toda a coletividade.

A Regulação da saúde também foi muito bem explanada, em um artigo que traz uma visão panorâmica sobre a estrutura e a dinâmica da ANS e ANVISA, apontando os desencaixes entre algumas teorias econômicas e a realidade das ações de saúde. A importância do Ministério Público para o fortalecimento do controle social da saúde, potencializando e atuando para a consolidação da democracia sanitária, por meio da participação nas Conferências e Conselhos de Saúde também foi relatado neste módulo.

Fechando as discussões deste eixo, é trazido à baila da discussão a relação entre os serviços públicos estatais e os serviços privados (com ou sem fins lucrativos) sob a denominação de filantropia.

O quarto eixo temático, que trata da proteção da saúde e as vigilâncias, é aberto com uma abordagem conceitual da Vigilância em Saúde, introduzindo o leitor no tema e identificando as propostas políticas de organização das práticas de Vigilância em Saúde no âmbito do SUS. Este eixo também discute o papel social e a abrangência da Vigilância Sanitária, trazendo apontamentos sobre sua interação com o Direito à Saúde.

Já o quinto eixo temático, denominado sistema internacional e saúde, apresenta dois artigos que fazem uma discussão a partir da análise do cenário epidemiológico mundial, trazendo os desafios enfrentados pelos organismos nacionais e internacionais de saúde pública e as implicações geradas pelo Regulamento Sanitário Internacional, que deve ser visto como uma oportunidade para a promoção da saúde pública global.

O último eixo temático da obra, intitulado ética sanitária, apresenta um artigo que traz os parâmetros para a discussão da saúde a partir de fundamentos éticos das ações e políticas de saúde pública, tendo a bioética como referencial.

Sem sombra de dúvidas, além de enriquecedora, esta obra é leitura obrigatória para que quem deseja enriquecer seus conhecimentos no campo do Direito Sanitário. A multidisciplinariedade resultante da articulação entre o Direito e a Saúde, característica típica do Direito Sanitário, bem como a maneira didática com a qual a obra é apresentada, fazem deste trabalho um ponto de encontro entre conhecimentos e saberes. 
ALVeS, S. M. C; Delduque, M. C; NETO, D. N. (Org.). Direito Sanitário em Perspectiva. Brasília: ESMPU: FIOCRUZ, v. 2, 2013.

Distribuição gratuita por requisição do interessado para: prodisa@fiocruz.br

Recebido para publicação em 13 de novembro de 2014. Admitido para publicação em 20 de novembro de 2014. 